\title{
The Importance of Leadership on Business Ethics at Organizations
}

\begin{abstract}
Aferdita Dervishi
PhDc in Management. Professor, Department of Economy, University College "Biznesi", Prishtinë, Republic of Kosovo.
\end{abstract}

Economic and Information Technology Faculty, European University of Tirana, Albania

\section{Abstract}

The purpose of this paper is to board the issues dealing with the ethics code of behave, and the role of leadership on motivation of staff to lead up the effectiveness and quality work at organization. The paper presents ethic standards and their importance for the success and competitive priorities for organizations and institutions. The elaboration of paper is carried using normative and comparative method attended by secondary source of data in the form of papers, journals, books, web-pages and manuals of organizations. There are studied principles of the Code of Ethics in two organizations, Bus Eirenann of Ireland and Kosovo Privatization Agency of the Republic of Kosovo, handling the practical implementation of ethic codes in both cases. Next to written policies for ethics there exist failures and mistakes on the ethics at working place that is present in everyday life as a result of improper behave of someone. Ethic behaves have had the positive impact at organizations, while nonethic behaves have serious impact on the development of staff and it keeps away incitement of tacit knowledge, obstructs innovations and creative work. Development and approval of ethic code and ethic practices at organization will not stop non-ethic behaves, but will give to people a kind of measurement versus which behave may be measured. Executive leaders at organizations and institutions should assess if the written or unwritten code is not respected so that the employees to feel safe for their integrity and appreciated.

Keywords: ethics, behave, integrity, faith, business ethics, leadership.

\section{Introduction}

This paper is concentrated on the study of ethics in generally as important part of organization's development and in particular business ethics at organizations or institutions as well as ethics practices. The paper contains the concept of leadership, the role of ethical leader and studies the components of business ethic code that are constituted by following factors: integrity, confidentiality, trust, respect, responsibility, impartiality and lawfulness. Examples of important companies that are committed to be sustainable in the market have paid particular attention to ethics. Multinational Corporation "Procter \& Gamble", believes on fair competition, as expressed their CEO: Our reputation is gained from our behave: what we say, but most important is what we do, our product, service, way of our behave and how we treat people. Other example may be noticed at the Waterford Institute of Technology (WIT), that have established politics for maintenance of high standards of ethics for the researchers, in 
order to protect research and results, as well as to continuously motivate researchers not only financially on different projects but also through making attractive environment for new ideas and innovations.

The main aim of this paper is to research the successful practices of business ethics implemented at an Irish company and institution in order to present a good model to follow.

The main research question is: What are the important points to be taken into consideration by supervisors related to respect of staff and ethics at organization in order the company to be successful and comparative?

In the paper are presented ethics standards and their importance to the reputation and success of the enterprise. There are analyzed the practices of ethics in one international organization, Business Ethic Code for Directors at 'Bus Eireann' (Ireland) and The Code of Ethics at Kosovo Privatization Agency (Kosovo), that is local institution.

\section{Literature Review}

Leadership is described as the process of social impact in which one person can get assistance and support of others, meaning having followers, in achievement of joint purpose. The leader is a person who influences a group of people and the desire to achieve a specific result (DeRue \& Ashford, 2008). Good leaders possess the power of will and desire to achieve something they are determined to. The manner supervisors behave to the staff is certainly one among important factors related to motivation of staff towards their commitment and work effectiveness in achieving better results, as well as their inducement for creative work and innovations. Hence, executives will have to accept the fact that moral impact of their supervisory presence and behave cannot be neutral,

Ethics mean standards of behave that determine how we should behave considering firstly the principles of what is good and what is bad, what is right and what is wrong, what to do and what not to do. But something right again depends on the situation and cultural environment as well as on the situation the activity is undertaken. Ethical behave is something based on personal values and on fairness of somebody, that may have origins to inner spirit, education and general culture. Referring to Oxford Dictionary, ethics is "moral principles that govern a person's behavior or the conducting of an activity". By being moral, you are doing what is 'right'.

Ethical leadership means keeping the strong and respectful communication and open line between supervisors and their subordinates, respectively their staff. The ones who are supervised need to feel comfortable and free to flow up, to seek an advice, to talk about problems they may have in relation to work and their duties at working place. Meanwhile Simon Webley and Elise More (2003), in their five year study carried out in the period 19972001, have found that employees who were clearly committed to do business in the ethics manner have produced more profit and benefited a norm from 18\% higher than the ones who have not had this commitment into consideration. American Psychological Association and the Society research (Dennis \& Meola, 2001), points out that, personality as the most important factor on describing the individual differences between leaders, hereupon the accentuation is given to moral principles that are high standards of ethics and to the decisions based on ethical principles. Moreover, they consider that the decisions taken having in regard the ethics side, in most cases are the power that helps the ethical leader to make them clear 
organization and obligatory norm. The research paper of ERC's National Business Ethics Survey (NBES) found that leaders have direct impact on ethics culture of the company and employees respond good to strong leadership. Another interesting study "Strategic leadership of ethical behavior in business" performed at six companies in different industries at the United States of America; found that employees are more concerned about the integrity than for the rules and sanctions. Executives with an ethic vision can move themselves and their organizations forward, step by important step (Thomas \& Schermerhom \& Dienhart, 2004:10). Stephen Brenner (1992), business ethics professor, wrote: All organizations have ethics programs, but most do not know that they do. A corporate ethics program is made up of values, policies and activities which impact the propriety of organization behaviors.

One of the attributes for the success is distinction between the best practices of business ethics and its qualities. This ethic practices implemented by the high levels of enterprise and institution becomes the spirit of enterprise's culture, meaning that success or failure, reputation or disrespect, summarized as its integrity. Furthermore they have direct impact on tacit knowledge that mostly brings innovations and creative minds leading to competitive advantages of one's business. Interesting research study entitled "Does Business Ethics Pay? (Webley \& More, 2003), stresses the following social ethics standards to be important:

High standards of integrity,

Sincerity, trust and righteousness

Confidentiality

Community inclusion / staff inclusion

The level of created trust to community / staff

High responsibility

Respect to others.

Some organizations pay utmost importance to ethics behave and to rightful access to business activity or to work development. At Irish organization "Bus Eirreann", the politics of ethics have increased the reputation of organization and this enabled to be a stable and respected enterprise in the market. At the ERC Ethics Resource Center, the Fellows Program, Ethical Leadershipand Executive Compensation: Rewarding Integrity in the C-Suite (2010, pg.11), is highlighted that, when organizations have a strong ethical tone at the top, employees will collectively work to succeed through honest effort to deliver value to customers and help the company earn a profit - but always within the rules. Having experienced the hospitability and friendship of Irish people during my stay at the Republic of Ireland, it is intentionally used another sample of ethics. However it is widely known that Irish people pay utmost importance to ethics behave from their homes up to the institutions and organizations. Waterford Institute of Technology (WIT) is a very good example of it, which has established the policies for respect and maintenance of high ethics standards for researchers, for the protection of research work and protection of scientific results.

Big companies that are devoted to be sustainable in the market as the only manner to arrive this is on building up the values with partners by including in their work, economic, social, environment and culture ethic within their business strategy. A typical example of this is shown at the company Procter \& Gamble, at Our Values and Policies, (pg.19) that believes on 
fair competition, as expressed as follows: We believe in competing fairly because we all benefit from fair, free and open markets. We compete strictly on the merits of our products and services and make no attempts to restrain or limit trade. Chief Executive Officer of Procter \& Gamble is convinced the reputation is gained from their behave, and he expresses as follows: what we say, but most important what we do; the product we make, service we offer and the way we behave and treat others.

Returning to the Code of Ethics of Kosovo Privatization Agency (PAK), in the very beginning is placed Aristotel's saying, in Politics 1294a3-6: "And remember that this code does not solve all ethics problems. But, we should remind that if good laws are not executed, they do not establish good governance". Further the 'Code of Ethics' regulates the rules of conduct and behave for the staff and management of the Agency, taking particular attention to confidentiality.

\section{Practical Arguments}

At all Ethics Codes of cases that were studied is pointed out that it is not possible to mention each situation that may occur in everyday life. If there is ambiguity or distinction regarding a certain case or situation, than it should be consulted the chairman or a competent organ. The interesting study of six companies of different industries at the United States of America,"Strategic leadership of ethical behavior in business" (Tomas, Schermerhom and Dienhart, 2004), where are shown two studies of ethics and behave of employees, one in a multinational company and another in a single company. According to findings, employees are more concerned about integrity of their working place rather than for the rules and sanctions. The employees of companies with the programs of integrity report lower incidence of non ethical behave and illegal works, bigger engagement at working place as well as planting of ethics in everyday decision making.

ERC's National Business Ethics Survey -NBES (2009), research found that leaders have direct impact on the culture of ethics at their company and the employees respond very good to strong leadership. Furthermore is believed that ethics behave and leadership must become the key written components of performance margins of each executive leader or director. Hereupon ethics is bind with financial reward of executive leaders (CEO) and the members of Leading Directors of the Board. However in our study for the Code of Ethics at "Bus Eireann" enterprise, managed by Board of Directors (BD), there are emphasized seven principles of the code of ethics. Following is the elaboration of these principles:

Integrity: Each director of 'Bus Eireann' during his/her work will respect the higher standards of integrity and sincerity, by being committed:

for an energetic but ethic competition;

to ensure that purchase of products / services is carried in accordance with best practices and procurement politics;

to avoid misinterpretation of position or of being unclear

not to use the sources of enterprise or time for personal benefits that are not linked with 'Bus Eireann', as well as to abuse with enterprise's means of transport

as director of Board cannot act in a way to decrease reputation of 'Bus Eireann' 
to ensure that reports / accounts of 'Bus Eireann' reflect the business performance of businesses and they are not misused or designed to be misused and other principles.

Privacy of information: For any information required for the enterprise the request should be directed to the Secretariat. For staff and Board of Directors the enterprise has "Guideline for issuance of information's" that must be respected, while for the public 'Bus Eireann' publishes information related to company's activity and performance on the web-page, that is regularly updated with new data. Each director of Board is obliged to keep in confidence the secret information's, whereas the documents that are used during hearings and meetings must be returned to the secretariat of enterprise.

Lawfulness: Board of Directors is required to ensure that activities of "Bus Eireann" are in accordance with the applicable law of Ireland and EU. Thus Board of Directors ensures that regulations are in accordance with enactment, ethics and standards of transport; that 'Bus Eireann' to cooperate with regulative and supervising organs; to offer fair and effective competition; procurement procedures are clearly described and respected as well as other procedures are fairly written and are respected.

Faithfulness: From each director of the Board, is required to be responsible and trustful to 'Bus Eireann' and fully committed to company's activities having in mind the interest of shareholders. It is also a requirement to perform their work based on high ethics standards.

Impartiality: The directors of the Board are obliged to act in accordance with the employment policies and legislation related to gender equality.

Responsibility: This principle involves the responsibility of the members of BD to incorporate the politics of discovering interests which they should save safely accept and confirm the politics and ethics code of 'Bus Eireann'.

Presents: Board of Directors can take presents from suppliers or from contractors if the present does not exceed the amount of €130 during a calendar year. As a gift is considered, bottle of wine, a calendar or something similar. In other cases the presents must be returned.

Board of directors of the 'Bus Eireann' is eligible to engage an independent professional expert, with the purpose to carry out the duties and obligations in best possible manner, in accordance with Ethics Guideline.

The second analyze is the study of 'Code of Ethics' of Privatization Agency of Kosovo (PAK), an Agency established by the Parliament of Kosovo, engaged with privatization of Socially owned enterprises and liquidation of their assets. Privatization Agency of Kosovo is directed by the Board of Directors. Among other policies and regulations it is approved the 'Code of ethics' with the purpose to respect the standards and ethical practices of business for the leading staff and employees of PAK. Three main principles determined by PAK are: indisputable trust, high performance and total engagement. The principles of the ethics code at Privatization Agency of Kosovo are elaborated below:

Respect to employees: According to this principle at PAK, it is not allowed the discrimination on gender, age, nationality, and religion or color basis. There is no discrimination on gender and religion base, while it is present a dose of disrespect from some supervising staff to some staff and pressure that de-motivates certain employees. 
Accordance with Laws and Regulations: The regulations of PAK and Code of Ethics are in accordance with Kosovo laws, offering needed resources in disposal at any time, and for violators are mentioned correcting actions and responsibility.

Confidentiality of information: this ethical principle is very important for PAK because of very sensitive information related to Socially Owned Enterprises, buyers, potential bidders and other stakeholders. This information cannot flow out neither to display to someone outside. The confidential information may be distributed outside the Agency only through written authorization, while its misuse leads to criminal follow-up, penalty and custody. The patents, licensees and trademarks are protected in cases of tender announcements for privatization and liquidation. The staff of Agency does not have unlimited access to information's, thus depending from the nature of their work they carry out, it is allowed specific access to information from Information technology head by written request of director who is supervisor of certain staff member. The information for the public is published at the web-page of PAK.

Conflict of interest is important standard because of the nature of work linked with property, business and activity of Socially Owned Enterprises as all of them are managed and privatized by PAK. It is not allowed to participate to a decision making process where the buyer or stakeholder is someone from family or relative.

Presents and compensations: there are not allowed the presents and compensations as well as other unauthorized favors. In any case if there is offered a small gift to a staff member, he or she should inform for that to the Department of Human Resources immediately.

Relations with outsiders: PAK have in disposal a wide specter of individuals, contractors, entrepreneurs and different companies, government and regulators, internationals and other stakeholders, therefore everyone at the Agency no matter from the position is obliged to offer quality and value of services. In order to maintain the relations created on trust and cooperation it is needed to everyday build the culture of trust according to clear and highest standards of integrity and objectivity, and ethical standards in generally.

At Privatization Agency of Kosovo (PAK, 2017), ethic standards are obligatory for everyone and each violation of code may result to disciplinary measures. It is also observed that until the selection of Managing Director, it was no disciplinary commission that could consider the violation or non violation of ethical standards. Except it recent years is appointed the Officer for Standards that is dealing with several issues linked with official standards.

Returning to our research question: What are the important points to be taken into consideration by supervisors related to respect of staff and ethics at organization in order the company to be successful and comparative? From the comparative study and other arguments of authors, the most important principles to be attained by supervisors are respect, integrity, lawfulness and impartiality.

\section{Conclusions}

In this paper is elaborated the business ethics and its importance at the organizations and their employees. Development and approval of code of ethics and ethical practices in organization will not stop unethical behaves, but, will give to people a kind of measure to assess behave. Ethical issues are in the focus of public and media. In Kosovo and wider we hear at TV and other media about the politicians of Kosovo that are accused for non-ethical 
behave, for nepotism, for the way of collecting or declaring donations for electoral campaign and other issues. For some institutions like Ministry of Transport and Telecommunications', Ministry of Education, Science and Technology, Central Bank of Kosovo and so on, the attention was placed on unacceptable practices and doubts for misuse, investigation for corruption and taking of bribe (Ref. Reports on TV, media, Anti Corruption Agency). All this reflects violation and unethical behave meaning disrespect of integrity, legacy and responsibility, by which is blenched the image of institutions and reputation of our country.

Executive leaders at organizations and enterprises, firstly themselves should be a sample of respect of ethics code by respecting properly and treating their staff in professional manner as well as graciously without distinction of post, title or influence. At PAK is mainly felt toxic organization culture, where employees in some sectors are not feeling appreciation and appraised. The lack of communication and the view from above created an environment that is not open for new ideas. Instead of this would be good for executive leaders to be involved in coordination of activities by which to motivate employees and then employees would feel respected and appreciated. The PAK Code of Ethics' must be reviewed and amended. Alan K. Simpson said ... If you have integrity, nothing else matters. If you don't have integrity, nothing else matters, hence besides legality this code needs to be completed with Integrity that is one of the main ethical standards. Meanwhile by analyzing the 'Code of Ethics' of 'Bus Eireann' (Ireland), is seen that the code is in compliance with objectives, business activities in the field does not contradict with the ethics and they are in the harmony with higher ethical standards including integrity, lawfulness, faithfulness and other standards. Even if this code is very completed and is referred strictly to each article and each section regulating this issues, it is foreseen that at least once in two years it should be reviewed and amended.

With numerous pages and articles of ethics code and policies, code of behave, organization values and laws, again there are profligacy and mistakes on the ethics at working place that are represented in everyday life that may come up from improper behave of somebody. Everyone at the working place should apply to the policies and procedures. Executive leaders at organizations should be more closer to employees, to organize sessions for prove search in order to see if the written of unwritten code of ethics is not respected. This work must be done in full confidence so that employees to feel safe for their integrity. The base for functioning of the code of ethics in organization is on the hands of executive leaders that must be firmly educated and supplied with personal culture and ethics. They will direct the implementation of ethics code because the reputation and integrity of organizations or institutions are too important to be left to the circumstance or chance, and this must Privatization Agency of Kosovo respect as well.

At this time of rashly technical-technological developments, where the competition is huge and globalization is spread all over, the ethics in business practices is becoming more and more important in professional education as well as in the academic education. A leader or an executive officer must bring the high standards of ethics in the working place every day, which is a culture contained by values, norms and respect.

\section{References}

[1] 'Bus Eireann', Code of Business Ethics for Directors, at: www.buseireann.ie/ 
[2] D. Scott DeRue, Susan J. Ashford (2008), Who Will Lead and Who Will Follow? A Social Process of Leadership Identity Construction in Organizations", Positive Identities Conference,

[3] Donna Dennis, Deborah Meola (2009), Preparing for Leadership, by American Management Association. Published by AMACOM Books, New York, , pg.115

[4] Donna Dennis, Deborah Meola, (2001), Preparing for Leadership, New York

[5] ERC Fellows Program (2010), Ethical Leadershipand Executive Compensation: Rewarding Integrity in the C-Suite, ERC Ethics Resource Center

[6] Ethics Resource Center (2009), National Business Ethics Survey: Ethics in Recession, at: http://ethics.org/nbes/

[7] Kosovo Privatisation Agency (2015)'Code of Ethics', Prishtina, Kosovo

[8] Lynn Sharp Paine, Does Ethics Pay?, Business Ethics Quarterly, 2000, Business Documentation Center, Volume 10, Issue 1, ISSN 1052-150X

[9] Privatization Agency of Kosovo, at: https://www.pak-ks.org/page.aspx?id=2,31

[10] Procter \&Gamble, Our Values and Policie, at (http://www.pg.com)

[11] Simon Webley, Elise More (2003) "Does Business Ethics Pay? Ethics and financial performance, Institute of Business Ethics, London SW1P 1BE

[12] Stephen Brenner (1992), Behavior Aspects of Business Ethics, Journal of Business Ethics, V11, pp. 391-399

[13] Terry Thomas, John R. Schermerhorn, John W. Dienhart, Strategic leadership of ethical behaviour in business, Academy of Management Executives, 2004. vol 18. No.2, pg.65

[14] Waterford Institute of Technology (2010), Research \& Knowledge Transfer Strategy, Ireland 